\title{
Students' Use of Summary in a Writing about Writing Class
}

\author{
Thomas Girshin \\ Ithaca College, Ithaca, USA \\ Email: tgirshin@ithaca.edu
}

How to cite this paper: Girshin, T. (2018) Students' Use of Summary in a Writing about Writing Class. Open Access Library Journal, 5: e4648.

https://doi.org/10.4236/oalib.1104648

Received: May 7, 2018

Accepted: November 23, 2018

Published: November 26, 2018

Copyright ( 2018 by author and Open Access Library Inc.

This work is licensed under the Creative Commons Attribution International License (CC BY 4.0).

http://creativecommons.org/licenses/by/4.0/

\begin{abstract}
This study explores whether or not a Writing about Writing (WAW) course design has a positive bearing on students' use of summary in their researched arguments. It hypothesizes that students will draw more on summary in their researched arguments, since students in WAW actively interpret a shared group of texts through the lens of the discourse community and thus have a higher level of comprehension of the source materials than if they sought out the source materials on their own. Borrowing the source-coding methods of the Citation Project (CP), the study provides data in response to the following questions: How do students use sources when asked to compose a written formal research project in the context of a course in which the sources they draw on are assigned as part of the course material? How does student source use, particularly with respect to summary writing, compare with available $\mathrm{CP}$ data in which students may or may not have drawn on assigned texts? Ultimately, it finds that students in the WAW course draw on summary at a significantly higher rate than in the CP.
\end{abstract}

\section{Subject Areas}

Education, Linguistics

\section{Keywords}

College Composition, Writing Pedagogy, Summary-Writing, Assessment

\section{Introduction}

Summary is an important part of academic discourse [1] and yet underused by first-year writers [2] [3]. The underuse of summary may be related to its difficulty, as it requires writers to form an understanding of the source text far greater than other forms of borrowing [4]. Whereas even direct quotation with 
little to no comprehension of the source text may be effective, even if accidentally, and effective paraphrase requires only comprehension of the sentence(s) being paraphrased, summary of a text in its entirety requires a minimal level of understanding of that text in its entirety [3]. Students may avoid summary in their written work because they lack the necessary cognitive maps to carefully read and comprehend a text, or because they do not see reading comprehension on that level as necessary [5]. Early research on how students draw on source texts shows that students tend to summarize by paraphrasing what they perceive as "privileged" sentences, rather than on the main ideas in that text [4]. The same study shows that these sentences are chosen inconsistently, suggesting that there is little agreement among student readers as to what the most important details of a text may be. Indeed, Johns \& Paz [6] indicate that students tend to have difficulty identifying the major structural components of source texts as a strategy for reading comprehension.

The link between summary and reading comprehension is well established. Roig [7] [8] shows a direct correlation between use of summary and comprehension of source texts, and further that the quality of paraphrase, defined as drawing on less source language, increases with text comprehension. Moreover, summary writing has been found a useful tool for assessing reading comprehension, since the cognitive strategies involved in summary parallel those involved in reading comprehension [5]. Anderson \& Pearson [9] argue, understanding a text is not a matter of objective deciphering, but rather of situating that text within the reader's subjective context. Accordingly, Hoye [10], Baba [11], and Gao [12] show a positive correlation between summary writing instruction and reading comprehension.

Summary also appears to be deeply intertwined with analysis. Van Dijk \& Kintsch's study of summary writing processes suggests that textual analysis-especially of structure-is necessary for summary writing, even though analysis may not lead directly to effective summary [13]. Moreover, the act of summarizing is itself complex, requiring sustained engagement with a text. Summary is the only intertextual strategy that asks the writer to present a reading of the source text as a whole, and is the only intertextual strategy that requires the writer to formulate an interpretation of a text at the level of its overall argument. Indeed, Baba's [11] study of 68 Japanese undergraduates demonstrates a pronounced link between sustained analysis of a text and the ability to write effective summaries of that text. The study indicates that writing effective summaries is more directly related to a reader's analytical engagement with that text (e.g. writing out definitions of key words) than with such factors as one's lexical breadth.

The Citation Project, a multi-institution analysis of the textual borrowing practices of students in first-year writing, highlighted the importance of increased attention to summary writing in first-year writing pedagogy [14]. While results of The Citation Project show that students are unlikely to use summary as 
a strategy for engaging with sources in their researched argument papers, they do not account for certain input variables, such whether sources are chosen by the instructor or by the individual student writer. Other studies, on the other hand, look at compulsory summary writing in which subjects are asked to write summaries of source texts in order to participate in the study. Given that summary is so tightly correlated with important literacy practices such as reading comprehension and analysis, more research is necessary to determine whether or not a writer is more likely to choose to draw on summary writing when the source texts are overdetermined by the course instructor. One objective of the present study is to replicate, albeit on a much smaller scale, the analysis of The Citation Project while taking into account more details about the course from which the papers are drawn. Specifically, this study identifies the content of the course as a Writing about Writing (WAW) course, and also identifies whether source texts are first identified by the student or by the instructor. In this study, the majority of source texts was assigned as part of the reading list for the course, and were analyzed and discussed in class before students began working on the major writing project. A working hypothesis in the present study is that the WAW content of the course will provide students with the threshold level of comprehension necessary to significantly increase their use of summary as a borrowing strategy in their researched argument paper. The present study provides data in response to the following questions:

1) How do students use sources when asked to compose a written formal research project in the context of a course in which the sources they draw on are assigned as part of the course material?

2) How does student source use in a WAW course, particularly with respect to summary writing, compare with available data in which students may or may not have drawn on assigned texts?

\section{Writing about Writing}

The course from which these papers were drawn asks students to learn about and ultimately make moves to join the Writing Studies discourse community. This is relevant because although students were supported in seeking sources beyond those assigned as part of the course itself, they nevertheless had a significant corpus of shared works on which to draw, as well as numerous class discussions of these works to help develop their interpretation of them. Students could be expected to have a better comprehension of these texts, not only because of opportunities to ask questions and make interpretations in class, but also-since assigned texts were in conversation with one another-because the comprehension of the texts was both cumulative and recursive. For example, a student's comprehension of a text like Richard Rodriguez's "A Public Language" would help with their comprehension of Gee's "Literacy, Discourse, and Linguistics: Introduction", and vice versa [15]. In addition, because the course had a specific content component in which I was an expert, students may have been 
able to draw much more heavily on assigned texts in their formal papers.

Writing about Writing (WAW) is a loosely circumscribed approach to first-year writing that puts writing studies at the center of the course. The approach was probably publicized most with the appearance of the textbook Writing About Writing: A College Reader [15], which is the textbook assigned in the classes described in the present study, but was around well before 2011. Downs \& Wardle [16] characterize the WAW approach as "Introduction to Writing Studies". Because Writing Studies is a diverse field, with many interests and methodologies, a first-year writing class following a WAW model can likewise take any number of diverse approaches. The point is that in a WAW course the focus "is always writing: how people use writing, how people learn to write, how genres mediate work in society, how 'discourse communities' affect language use, how writing changes across the disciplines, and so on. The research is about language, the discussions are about language, and the goal of the course is to teach students the content of our discipline" [17]. Wardle [17] argues that, because writing is such a complex activity that occurs within and is deeply affected by relevant activity systems, there is no possibility of teaching general writing skills. There is no such thing as writing in general, or even academic writing in general. Therefore, "specialized writing is best taught by reflective insiders who know the genres and their content, in the activity systems where those genres mediate (and are informed and shaped by) meaningful activities" [17]. This calls for a rigorous WAC strategy, which would help students write like a scholar in their fields of study. The role of FYW, to address its institutional mandate, to be ethically responsive to the needs of students, and to continue the scholarly missions of the field, is to teach students something about what it means to be a scholar, what it means to engage with experts in a field, as an expert. Wardle's critiques of FYW's mission to teach general writing skills in fact resonates with David Bartholomae's [18] argument that the work of academic writing instruction is at least in part identity work, teaching students how to recognize and mimic the conventions of academic discourse.

WAW emphasizes this sort of discourse familiarity by helping students to engage in a writing studies discourse community. WAW "[introduces] students directly to what writing researchers have learned about writing and challenging them to respond by writing and doing research of their own" [15]. Thus, WAW takes writing studies itself as the content of FYW, rather than supplementing with writing instruction on top of some other course theme. One of the basic premises of WAW is that, by giving students opportunities to learn about writing studies research, conduct their own related research (including self-studies), and write in the genres of the field, WAW will [change students'] understandings about writing and thus [change] the ways they write [15]. Given that discourse familiarity is directly related to reading comprehension, and that reading comprehension is directly related to summary writing, it may be that greater discourse familiarity would correlate with greater use of summary. To the extent 
that WAW works to develop students' familiarity with the discourses of writing studies, then, it is likely that students' use of summary would be higher in a WAW course than when readings vary according to mode or theme, particularly in classes where students are individually responsible for identifying and making sense of their sources. I wondered if this familiarity would correlate positively with the use of summary in students' formal work. Moreover, given that there has been some criticism of the WAW approach as insufficiently interesting for first-year students, I wanted to learn whether or not students needed to be especially interested in course material to engage highly with course texts. For this reason I administered a survey to measure student interest in the course texts.

\section{Methods}

This mixed-methods study draws in part on the methods of The Citation Project, though is not affiliated with that larger study. After obtaining IRB clearance, I gathered a random sample of 16 student papers written in three different first-year writing (FYW) courses at a Carnegie classified M1 university. Because there has been some question in the field whether or not WAW is too challenging for first-year students, I also administered a survey to the same students to gather data about their attitudes toward course materials and writing opportunities [19] [20]. Each course began fully enrolled at 18 students, for a total of 54 students. Most students enrolled (42) were first-year students; 12 were sophomores.

\subsection{Coding}

Of the 54 students enrolled at the beginning of the semester, 3 withdrew from the course before the end of the semester, and thus did not turn in a final project. One other student remained in the class, but did not turn in the final project. The total number of students who had turned in projects that could be analyzed for the coding portion of the current project is 50 . Out of these, 16 papers were randomly selected for analysis. Gender identity and other identifying information were removed from all the papers prior to randomization, and so are not relevant to this study. Randomization was achieved by assigning a numerical value to each paper $(1-50)$, and then generating a random string of 16 numbers (out of the limit 1 - 50) using the random number generator at random.org.

Each course was taught by the author, and followed a Writing about Writing (WAW) pedagogical framework. The papers coded were composed in response to the final major course project, called Literacy Revised (Appendix 2). The project asks students to build on the prior work they had done in the class, in both their reading and writing assignments, to write a researched argument that engages current conversations in literacy and writing studies. Prior to the undertaking of the Literacy Revised project, students were instructed in how to write summaries using the guidelines 1) read the original text carefully, taking 
marginal notes as you read; 2) focus on the overall argument the text is making; 3) provide only the most effective or important examples from the text; 4) avoid commenting on or adding to the original text; 5) write an opening that identifies the source and provides some context; and 6) keep the summary to no more than 500 words. Students worked on summary writing in class and as take home assignments. In addition, to help develop students' abilities to identify the "macrostructure" [6] of the source text students drew on the work of Johns [1] and Swales [21]-particularly the CARS structure adapted by Wardle and Downs [15].

The author worked with an undergraduate research assistant to code only the first five pages of these 16 randomly selected papers according to the scheme described in the CP: copying, not marked as quotation; copying, marked as quotation; patchwriting; paraphrasing, and summarizing. The author chose to begin with the first page, rather than with the second page as in the $\mathrm{CP}$, because the study had fewer papers to analyze and so limiting the amount of data to analyze was not an issue as it was in the CP. As with the CP, the present study defined patchwriting as drawing on source text with minor changes to syntax and diction, insufficient to effectively distinguish the borrowed language from source language [3]. As Howard suggests, patchwriting is a source-use strategy writers often draw on when faced with difficult situations [22]. Moreover, she suggests that patchwriting is an intermediate stage through which students pass as they work on entering new discourse communities [22]. As stated above, this study is concerned primarily with the use of summary. However, other forms of borrowing from sources were also coded in order to help contextualize the use of summary.

Following Howard, Serviss, and Rodrigue, the present study defined summary as "restating and compressing the main points of a paragraph or more of text in fresh language and reducing the summarized passage by at least 50\%" [3]. To test for interrater reliability, each paper in the sample was coded independently by two coders. Interrater reliability for coding of all 83 codable instances of source borrowing was calculated using a simple percent agreement formula. A sample of text was considered codable only if both coders identified it as such independently.

Coding proceeded by first identifying sentences in the paper that drew on other sources, as indicated by reference to a source in the text. For example, the sentence may end with a parenthetical citation, if direct quotation or paraphrase was the method of borrowing. In the case of summary, a sentence may introduce a source by title and author, and some transitional phrase may indicate where the summary ends. If no such phrase were found in the paper, coding would stop at the end of that paragraph. Any text that has neither a direct nor a parenthetical reference to a source text was not coded, even if the language was identical to or highly similar to a source text. As in the $\mathrm{CP}$, each individual citation was numbered continuously from the first paper coded to the last. The source 
used for each citation was also identified and labelled, as was the page in the original text from which the citation was sourced. If more than one source was mentioned in a single citation, this was noted as well [14].

\subsection{Survey}

The survey consists of nine questions, including some questions asking about demographic information as well as questions designed to measure a basic level of positivity/negativity toward course texts and the extent to which a given student would have liked more opportunity to pursue individual research on the subject of writing studies. See Appendix 1 for a copy of the survey questions in full. Students were first presented with informed consent forms, which apprised them of the nature of the study, implied risks, and of their freedom to opt out of any part of the study. Forty-three (43) students signed the consent form, and 39 students completed the survey. Students completed the survey either online or in paper format, depending on their preference. Twenty-two (22) students completed the survey online; the remaining 17 completed it using the paper form. All but 1 of the 39 students completing the survey indicated their class standing as freshman; however, because some students came in with college credit from high school or transfer classes, they may have had sophomore standing, and would be counted as sophomores in the figures. Twenty-five (25) identified as female; 15 identified as male.

\section{Results}

\subsection{Survey Results}

The survey results show that student attitudes toward course texts were not overwhelmingly favorable. In Question 6, students responded to the statement "I enjoyed the assigned texts we read in this class" with a mean score of 2.513 on a scale of $1-5$, with 1 being disagree strongly and 5 being agree strongly. Based on this score, students overall neither enjoyed nor did not enjoy course texts. They were indifferent to them. This indifference is qualified by student responses to Questions 8 and 9. Question 8 asked students to list their favorite texts from the class. Five students left this question blank, suggesting that 1) they could not think of their favorite text, 2) they did not have a favorite text, or 3) they did not wish to complete this portion of the survey. The remaining 34 students did respond to this question, with half (17) choosing a single text from the class, and the remaining choosing a range of $2(\mathrm{n}=10)$ to $5(\mathrm{n}=1)$. The single most popular text assigned in the class was Gee $(n=8)$, followed closely by Johns $(n=7)$ and $\mathrm{X}(\mathrm{n}=7)$ (all in Wardle \& Downs, 2011). Gee and Johns are both scholarly articles focused on academic discourse, while $\mathrm{X}$ is a portion of a memoir.

Question 9 asked students for any additional comments. Many students used to this space to clarify their attitudes toward the course texts and their relationship to writing. Several students expressed that the texts were "dry", "boring", and/or "long". One student wrote: 
This [is] the first time that I came in contact with academic pieces and discourses on literacy like the ones we have been reading and I found them very difficult to understand because I wasn't always sure how to approach them.

Another student agreed that one reason the texts were not enjoyable was that they were difficult to understand. The student commented "Sometimes felt like the concepts were over my head, did not fully understand topics which lead [sic] to lack of understanding of the texts.

Not a single student wrote that they enjoyed the texts, which given the responses to Question 6 is not surprising. Nevertheless, a trend emerges in the final comments in which students seem to appreciate what they learned from the texts, even though they did not enjoy them. For example, a student wrote that though the book was "boring", it "felt necessary". Another student wrote "I feel that although the texts were not particularly fun to read, they were very constructive and they helped me understand how to write in an academic setting".

Question 7 asks students to state the extent to which they agree with the following statement, following the same numerical scale as in Question 6: "I wish I had the opportunity to pursue my own research (library or primary) related to writing about writing in this class". The mean score in response to this question (2.514) was lower than that for the responses to Question 6 (2.542) - which shocked me. I say this because, as I was going over the surveys, inputting the data, I was sure the score for Question 7 was going to be significantly higher than Question 6. So when it came back the same I found myself double checking the numbers.

Upon further analysis, it appears that student attitudes toward their own research in the course differed in important ways from their attitude toward course texts. While the mean score for Question 7 is nearly identical to that for Question 6, both the median and mode are lower (see Table 1). This tells me that Question 7 was more polarizing than Question 6 (it also tells me that I was favoring the positive responses as I was entering the data). So, while overall students were not especially interested in pursuing independent research, many individual students were eager to continue studying writing practices. Question 6 had only three respondents choose a 4 in response, and no student chose a 5 . Question 7, in contrast, had five students respond with a 4, and one student

Table 1. Student interest in course texts compared with interest in student-conducted research.

\begin{tabular}{|c|c|c|}
\hline & $\begin{array}{l}\text { To what extent do you agree } \\
\text { with the statement "I enjoyed the } \\
\text { assigned texts in this class"? }\end{array}$ & $\begin{array}{l}\text { To what extent do you agree with the } \\
\text { statement "I wish I had more opportunity to } \\
\text { pursue my own research (library or primary) } \\
\text { related to writing about writing in this class"? }\end{array}$ \\
\hline Mean & 2.542 & 2.514 \\
\hline Mode & 3 & 2 \\
\hline Median & 3 & 2 \\
\hline
\end{tabular}


responded with a 5. Twice as many students were interested in pursuing more research than enjoyed the course texts. Of the six students who responded with a 4 or higher to Question 7, five responded with a 2 for Question 6, and one responded with a 3. So, at least for these students, interest in pursuing further research was significantly higher than their enjoyment of the course texts.

\subsection{Coding Results}

The total number of citations was 83 . Of those, one instance was copying not marked, 30 were copying marked, 6 were classified as patchwriting, 11 were paraphrasing, and 35 were summary. The average paper in this study had 5.19 citations, with a range of 2 - 11. The low incidence of copying suggests students understand their sources to a greater extent than if copying were their primary method of borrowing. Horning [23] and Roig [7] suggest that students who understand their sources are less likely to plagiarize. The relatively low level of patchwriting $(7.23 \%)$, too, suggests that students in this cohort had a high understanding of their sources [23]. These figures are also in stark contrast with the results of the CP's "Phase I Data" (P1), where students engaged in patchwriting at roughly double the rate. Even more striking however, is the difference in frequency with which students summarized their source texts in the two studies. In fact, and in significant deviation from the results of P1, students in the present study (WAW) drew on summary more frequently than any other strategy. Just over $42 \%$ of the 83 citations studied were classified as summary (see Figure 1). In P1, 6.28\% of the 1911 citations were classified as summary.

Not only did individual students in WAW draw on summary as a strategy more frequently than in $\mathrm{P} 1$, more students in this group drew on the strategy in general. In P1, $40.80 \%$ of papers included at least one instance of summary, while in WAW $87.50 \%$ of the papers drew on summary at least once. Students in WAW did not just draw on summary more frequently, they also drew on summary in greater distribution throughout the paper. Looking across the entire sample, P1 shows summary only on pages three and four (Figure 2).

\subsection{Equations}

By contrast, instances of summary appeared on every page of the five pages coded in WAW (Figure 3). Moreover, while P1 summary use peaks on page three, WAW summary use peaks a full page earlier on page two (Figure 2 and Figure 3$){ }^{1}$

The WAW study also generated some data that, because correlating data from P1 isn't available, can't be compared to larger trends. Nevertheless, this preliminary indicator of student source-use may prove fruitful for further research. The pattern evident in the coding is that in $62.50 \%$ of papers coded, summary ${ }^{1}$ The Citation Project begins coding at the second page of each paper, in order to "focus on the source use in the body of the paper where the students were most frequently engaging with researched material" [2]. The current project begins coding on the first page of each paper. This difference does not affect where summary use peaks in either corpus of texts. 


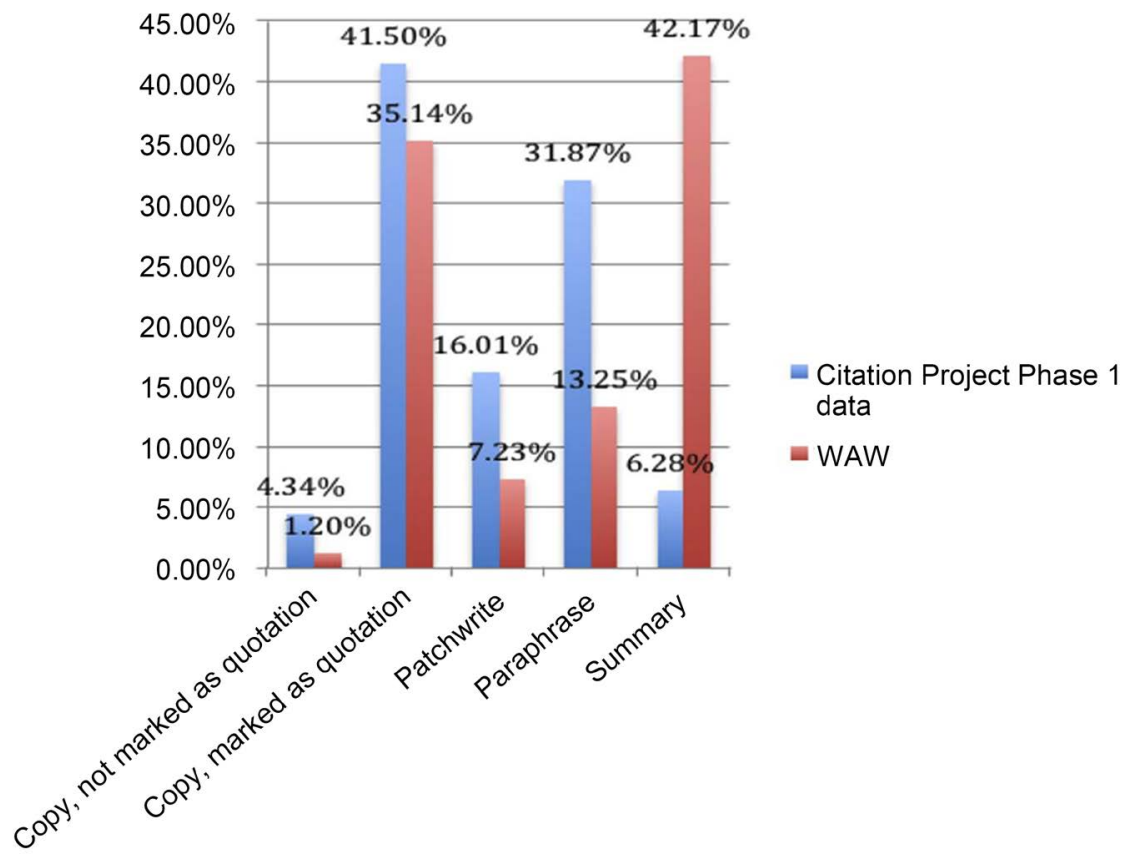

Figure 1. Incidence of different source use types, present study (WAW) and citation Project.

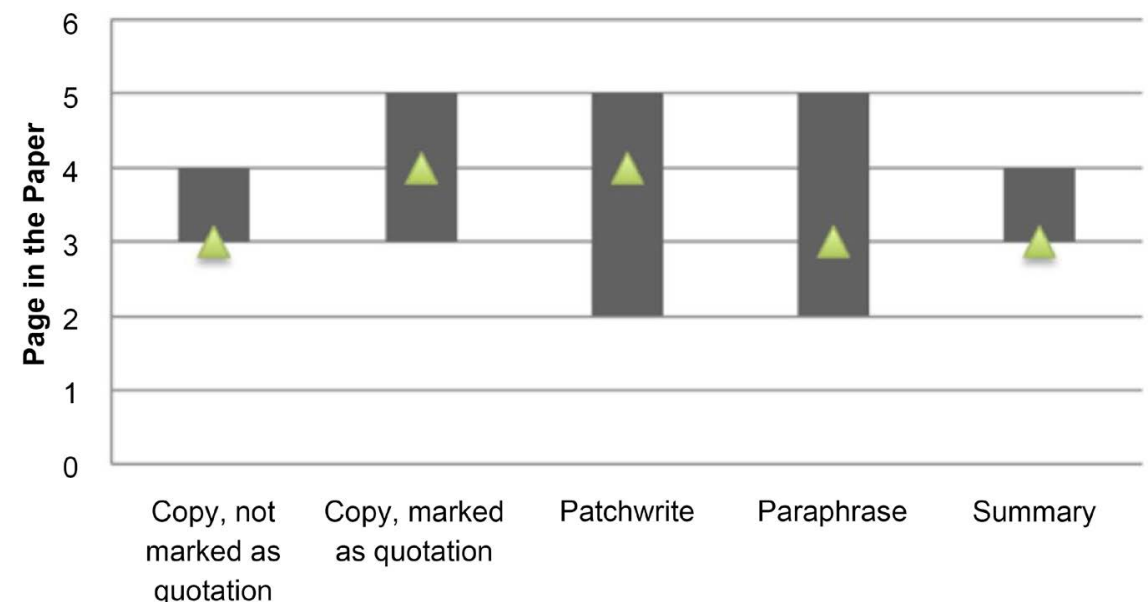

Type of Source Use

Figure 2. Citation project phase 1 data.

appeared in conjunction with or closely followed by another source-use strategy (i.e. copying with or without quotation, paraphrasing, or patchwriting). This kind of writing from sources using more than one method of borrowing may point to further engagement with the texts. Using multiple strategies indicates that the writer is asking the text to serve more than one purpose in her paper. For example, in the following excerpt from one of the papers studied, the writer draws on Wardle's "Identity, Authority, and Learning to Write in New Workplaces" [15] in order to borrow one of her main arguments: that becoming a member of a community required one to facilitate a reciprocal understanding 


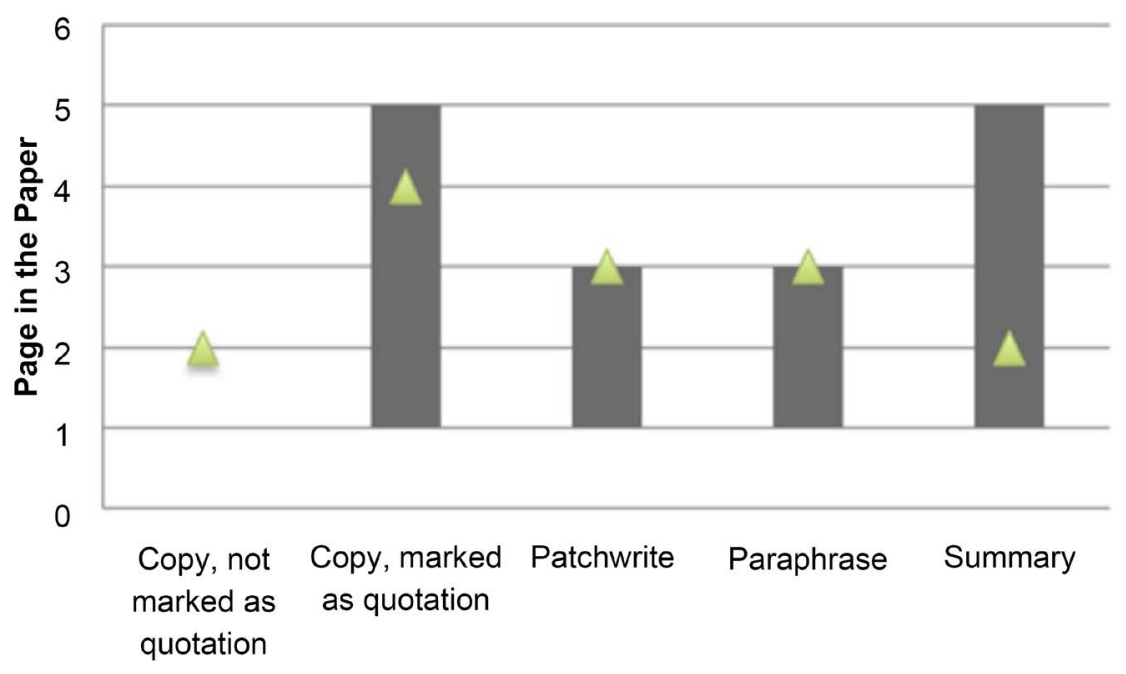

Type of Source Use

Figure 3. Present study.

of one's role in that community. At the same time, the writer wants to move beyond that general argument in order to isolate a more specific aspect of it: that this often means taking on community values, even at the expense of your own.

To belong in a new organization, in Wardle's example, the "fresh meat" Alan had to find a place where he would succeed in doing his job. Alan failed to "accept his basic assumptions about what [was] valuable and appropriate" in the discourse community, ultimately failing for the community to work efficiently (527) (\#5).

Similarly, in the following excerpt from a different paper, the writer blends summary with direct quotation in order to contextualize an idea, and then build from a specific aspect of that idea.

Richard Rodriguez, and his short article entitled "A Public Language" touches upon the difficulties of being immersed in a society in which the language was not familiar to him. Growing up in Sacramento in an all white neighborhood and school, only knowing Spanish, caused him much trouble as a child. At one point he references Spanish as his "private language" and discusses the implication of living in such a situation in which he can barely understand anyone (Rodriguez 194). Rodriguez also discusses how comfortable he feels at home while speaking his native language versus how uncomfortable he feels being the only non English-speaker in an English-speaking classroom. "For me there were none of the gradations between public and private society so normal to a maturing child. Outside the house was public society' inside the house was private" (Rodriguez 196) (\#12).

In addition to approximating the source-use strategies of expert scholars, this type of multi-strategy borrowing suggests a relatively high level of familiarity 
with and comprehension of the source text, in that it is able to make connections between the overall piece and some of is important details.

\section{Discussion}

The sample size $(n=16)$ and number of lines of prose analyzed (1852) is dwarfed by the larger CP study, which analyzed 17,600 lines of student work [2]. More research on the citation practices of students in WAW courses should be done, and this research should be compared with the ongoing research of the $\mathrm{CP}$, which in its second phase is coding for input variables such as whether or not students are drawing on shared course texts. Nevertheless, the trends presented above are meaningful, because they point to a relationship between reading and writing that is continuing to draw attention in the literature. The results emphasize what scholars in writing studies have long been arguing: that student source-use is based in large part on their knowledge of sources. This suggests that ethical arguments about plagiarism miss the mark when it comes to the vast majority of issues with student source use, in agreement with Valentine [24] and Horning [23]. Students draw on the writing strategies they do because-given how they understand the writing situation and their available responses-they actively or passively decide that these strategies are the best ones in that particular situation. At the 2012 Conference on College Composition and Communication, Anthropologist Susan Blum made the argument that the decisions students make-even those such as cheating and blatant plagiarism commonly considered unethical-are rational in that they are reasoned responses to a perceived situation (see also [25]). This view of the student as one who is struggling to succeed is at odds with popular notions of students looking to cheat out of sheer laziness or malice. It calls for pedagogical approaches that reward learning processes, and that better map proven learning strategies onto criteria for success in the classroom.

Given that summary use has been positively correlated with student learning, especially in terms of reading comprehension, and given its widespread use in published academic prose, it would be wise to pay greater attention to student use of summary in their writing projects. The increased use of summary as a textual strategy in the present study supports the possibility that students draw on summary more not only when they understand their sources better, but also when they better understand the rhetorical situation circumscribing those sources. While no large-scale studies of student attitudes to WAW courses have been published, the present study indicates that students are generally not immediately interested in the subject matter. While students were not highly interested in the course texts, many did write that they found the texts useful, and several students seemed to be inspired by the class to conduct further research on writing-even when the same students did not find the course texts particularly interesting.

The study suggests, then, that students came to engage with texts in the field 
in a highly involved way. Several students wrote in survey responses that they found the texts useful, even if they did not enjoy reading them. While popular notions of reading as a pastime reflect a view that reading is only valuable if it is enjoyable, the present study indicates an appreciation for the scholarly work of writing. The widespread use of summary in the present study shows, too, that students were reading the texts, and actively working to build understanding of not only the texts, but also the discourse of which these texts are examples. Students worked to involve themselves as members of the Writing Studies discourse community. Given this high level of involvement, it may be useful to rethink student engagement as a textual practice, rather than an emotional response to course content. Literature in writing studies has relied on the mostly implicit, and vague, definition that student engagement is an emotional or intellectual attachment to classroom activities. Recent work in writing studies situates student engagement in terms of service learning and/or public discourse [26] [27] [28]. Engagement in those cases is synonymous with interaction. In related fields like Education, inquiries into student engagement often take the National Survey of Student Engagement (NSSE) or the College Student Experiences Questionnaire (CSEQ) either as their methodological starting point, or as their source of data on the subject. These studies tend to measure engagement in terms of time spent studying and relative levels of difficulty with course material.

Porter, Rumann, and Pontius [29], along with Axelson \& Flick [30], argue that studies of engagement need to move away from measures of students' overall intellectual involvement with course phenomena-measures which "[obscure] some of the very phenomena [education researchers] seek to study"-and focus instead on specific ways students are being engaged in specific activities [30]. "That is, we might ask, 'How do we engage (cognitively, behaviorally, and/or emotionally) type $X$ students most effectively in type $Y$ learning processes/contexts so that they will attain knowledge, skill, or disposition $Z$ " [30]. These more targeted measures are necessary because, while general involvement in academic life, as measured by the NSSE for example, does correlate with several positive outcomes [31], it does not provide much information about the kinds of activities that lead to learning a given index in a given context. When it comes to writing, especially, it is important to know the specific instructional experiences that lead to the kinds of composing knowledge that is the stated learning outcome of a typical first-year writing class (FYW). While no research on the relationship between general levels of student engagement in FYW and learning outcomes exists, I'm skeptical that students' enthusiasm for any particular FYW class-when accounting for factors such as educational background, class, race, and gender, and student GPA-can predictably correlate with their learning outcomes in that class. For one thing, students' enthusiasm for a particular course theme (e.g. globalization or popular culture) might promote more attention to content related to that theme-which at most institutions does not bear on course outcomes-at the expense of attention to matters of writing which do directly bear on course outcomes. 
Given this call for more targeted measures of the intellectual work students are doing in a given class, I want to suggest that summary use may be the best tool for measuring student engagement. Following Porter, Rumann, and Pontius [29], then, and based on the results of the present study, students' use of summary in FYW can be identified as a valid and effective measure of student engagement, because it correlates with those mental tasks-reading comprehension and rhetorically aware composition-that bear most on learning outcomes. By redefining student engagement in FYC as student engagement with texts through writing, we can isolate use of summary to measure the extent to which students actively make meaning of texts, consider a text's parts in relation to its overall argument and its overall argument in relation to other texts. Moreover, students' use of summary is easily and accurately measurable through coding techniques, whereas relying on students' perceptions of their engagement with texts is more problematic. Thus, the coding of student texts, especially those written at or near the end of the semester, may be an effective measure of student engagement with texts.

\section{Conflicts of Interest}

The author declares no conflicts of interest regarding the publication of this paper.

\section{References}

[1] Johns, A.M. (1997) Text, Role and Context: Developing Academic Literacies. Cambridge UP, New York. https://doi.org/10.1017/CBO9781139524650

[2] Jamieson, S. and Howard, R.M. (2013) Sentence-Mining: Uncovering the Amount of Reading and Reading Comprehension in College Writers' Researched Writing. In: McClure, R. and Purdy, J.P., Eds., The New Digital Scholar. Exploring and Enriching the Research and and Writing Practices of Nextgen Students, Information Today, Medford Township, 111-133.

[3] Howard, R.M., Serviss, T. and Rodrigue, T.K. (2010) Writing from Sources, Writing from Sentences. Writing and Pedagogy, 2, 177-192. https://doi.org/10.1558/wap.v2i2.177

[4] Sherrard, C. (1986) Summary Writing: A Topographical Study. Written Communication, 3, 324-343. https://doi.org/10.1177/0741088386003003003

[5] Kintsch, E. (1990) Macroprocesses and Microprocesses in the Development of Summarization Skill. Cognition and Instruction, 7, 161-195. https://doi.org/10.1207/s1532690xci0703_1

[6] Johns, A. and Paz, D. (2004) Text Analysis and Pedagogical Summaries: Revisiting Johns and Davies. Functional Approaches to Written Text. TESOL France Journals, 2, 39-60.

[7] Roig, M. (1999) When College Students' Attempts at Paraphrasing Become Instances of Potential Plagiarism. Psychological Reports, 84, 973-982. https://doi.org/10.2466/pr0.1999.84.3.973

[8] Roig, M. (2001) Plagiarism and Paraphrasing Criteria of College and University Professors. Ethics \& Behavior, 11, 307-323. 
https://doi.org/10.1207/S15327019EB1103_8

[9] Anderson, R.C. and Pearson, P.D. (1984) A Schema-Theoretic View of Basic Processes in Reading Comprehension. Handbook of Reading Research, 1, 255-291.

[10] Hoye, M. (1989) The Effects of Summary Writing on the Reading Comprehension of American and ESL University Freshmen. Ph.D. Thesis, Dissertation Abstracts International, 49, 3291-A.

[11] Baba, K. (2009) Aspects of Lexical Proficiency in Writing Summaries in a Foreign Language. Journal of Second Language Writing, 18, 191-208. https://doi.org/10.1016/j.jslw.2009.05.003

[12] Gao, Y. (2013) The Effect of Summary Writing on Reading Comprehension: The Role of Mediation in EFL Classroom. Reading Improvement, 50, 43-47.

[13] Taylor, K.K. (1986) Summary Writing by Young Children. Reading Research Quarterly, 21, 193-208. https://doi.org/10.2307/747845

[14] Jamieson, S., Howard, R.M. and Serviss, T. (n.d.) Research Methods. The Citation Project. http://www.citationproject.net/

[15] Wardle, E. and Downs, D. (2011) Writing about Writing: A College Reader. Macmillan Higher Education, New York.

[16] Downs, D. and Wardle, E. (2007) Teaching about Writing, Righting Misconceptions: (Re)Envisioning "First-Year Composition" as "Introduction to Writing Studies". College Composition and Communication, 58, 552-554.

[17] Wardle, E. (2009) "Mutt Genres" and the Goal of FYC: Can We Help Students Write the Genres of the University? College Composition and Communication, 60, 765-789.

[18] Bartholomae, D. (1986) Inventing the University. Journal of Basic Writing, 5, 4-23.

[19] Miles, L., et al. (2008) Commenting on Douglas Downs and Elizabeth Wardle's “Teaching about Writing, Righting Misconceptions". College Composition and Communication, 59, 503-511.

[20] Charlton, J. (2009) Seeing Is Believing: Writing Studies with "Basic Writing" Students. Basic Writing E-Journal, 8-9, 1-9.

[21] Swales, J. (1990) Genre Analysis: English in Academic and Research Settings. Cambridge University Press, New York.

[22] Howard, R.M. (1992) A Plagiarism Pentimento. Journal of Teaching Writing, 11, 233-245

[23] Horning, A. (2009) A Potential Solution to the Plagiarism Problem: Improving Reading. Journal of Teaching Writing, 25, 143-175.

[24] Valentine, K. (2006) Plagiarism As Literacy Practice: Recognizing and Rethinking Ethical Binaries. College Composition and Communication, 58, 89-109.

[25] Blum, S.D. (2009) My Word! Plagiarism and College Culture. Cornell University Press, Ithaca.

[26] Clayton, P.H. and Ash, S.L. (2004) Shifts in Perspective: Capitalizing on the Counternormative Nature of Service-Learning. Michigan Journal of Community Service Learning, 11, 59-70.

[27] Hutchinson, M. (2005) Living the Rhetoric: Service Learning and Increased Value of Social Responsibility. Pedagogy, 5, 427-444.

[28] Flower, L. (2008) Community Literacy and the Rhetoric of Public Engagement. Southern Illinois University Press, Carbondale.

[29] Porter, S.R., Rumann, C. and Pontius, J. (2011) The Validity of Student Engagement 
Survey Questions: Can We Accurately Measure Academic Challenge? New Directions for Institutional Research, 2011, 87-98. https://doi.org/10.1002/ir.391

[30] Axelson, R.D. and Flick, A. (2010) Defining Student Engagement. Change: The Magazine of Higher Learning, 43, 38-43.

https://doi.org/10.1080/00091383.2011.533096

[31] Carini, R.M., Kuh, G.D. and Klein, S.P. (2006) Student Engagement and Student Learning: Testing the Linkages. Research in Higher Education, 47, 1-32.

https://doi.org/10.1007/s11162-005-8150-9 


\section{Appendix 1}

Survey of Attitudes Toward Writing about Writing.

I am conducting a study concerning students' use of sources in a first-year academic writing course with a Writing about Writing focus. Please complete this brief survey concerning your attitudes toward the course materials and projects. You may leave any questions blank and/or stop filling out this survey at any time.

When you have completed the consent form and/or survey, please place it/them in the envelope marked "Source Use Pilot" distributed with these forms. Please submit a survey only if you have signed the consent form. You may return a blank or incomplete survey.

DO NOT FILL OUT THIS SURVEY IF YOU ARE NOT AT LEAST 18 YEARS OLD.

Please tear off this cover page and keep for your records. Thank you for helping me with this project.

1) Name:

Knowing your name will help me contextualize source use in the papers. However, you may choose to skip this question and continue to fill out the rest of the survey.

2) Class standing when enrolled in this course:

Freshman

Sophomore

Junior

Senior

Other

3) Gender

Male

Female

Prefer not to say

Other

4) What is your major?

5) In addition to Academic Writing I in which you are currently enrolled, what writing courses have you taken in college?

Include other writing courses in which you are currently enrolled. Include Academic Writing I if this is not your first time taking it.

6) To what extent do you agree with the following statement?

I enjoyed the assigned texts we read in this class.

Disagree Strongly

1

2

3

4 
5

Agree Strongly

7) To what extent do you agree with the following statement?

I wish I had more opportunity to pursue my own research (library or primary) related to writing about writing in this class.

Disagree strongly

1

2

3

4

5

Agree strongly

8) List your favorite texts we read in this class.

9) Additional comments about course texts.

Include any additional comments in relation to the required texts in this course.

\section{Appendix 2}

Unit 3 Project Description-Literacy Revised Project Goals

- Become adept at the thesis/support arrangement pattern.

- Gain fluency in intertextuality as a discourse convention, including the effective use of Metadiscourse, citation, and MLA format.

- Situate an argument within a specific, ongoing, conversation.

- Draw on personal experience as evidence.

- Draw on relevant texts as evidence.

- Effectively use summary, paraphrase, and direct quotation as invention strategies.

- Effectively use analysis and reflection as revision strategies. Introduction

This semester we have looked at literacy in a number of different ways: by exploring our personal literacy histories and the literacy histories of others, by engaging in peer review and conversations about writing, by studying the concept of discourses and how these affect the way we work with language, by studying and practicing invention, arrangement and revision strategies, etc. One thing we have seen is that literacy allows us not only to consume texts, but also to participate in and contribute to the discussions that inform our lives as literate people. Our final course paper gives you the opportunity to revisit each of these methods of exploration to create a claim-driven, source-based text relevant to course concepts and practices.

Assignment

For this project you will reflect on our reading, writing, and discussion activities this semester in order to make a well-supported claim about some aspect of 
literacy. One of the main purposes of the assignment is to enter an ongoing conversation concerning literacy in the United States. Thus, your piece will work to define literacy in a way that is contextualized by some aspect or aspects of the conversation(s) in which you have engaged in this course.

Think back over your experiences, your writing, your insights, and our readings as you gather material and ideas for the paper. Ultimately, you will use course texts, your literacy experiences, insights from your previous papers (in this and other courses), and other appropriate materials to create an analysis that helps us to revise some specific ideas about literacy. Remember that analysis is often critique or inquiry-based-it doesn't take anything for granted. You want your paper to make a claim that is relevant to discourses of literacy as we have engaged them throughout the semester, and to support that claim with compelling evidence.

Your paper must be 6 - 8 pages long, use and cite sources appropriately and correctly, and contribute to the on-going scholarly discussions of literacy in the U.S.

Evaluation Criteria

MINIMUM STANDARDS (e.g. a "C" paper):

Focus

Makes a claim, but may not be specific or sufficiently relevant to discourses concerning literacy.

Purpose of text may be unclear.

Draws on at least one course text related to literacy.

Draws on personal experience related to literacy.

Working definition of literacy (may be explicit or implicit) is not fully fleshed out.

\section{Development}

Engage a text from the course related to literacy, but not in a substantial way. Include only minor direct quotation and/or paraphrase. Little or poorly developed summary. Analysis is minimal, unreasonable, or ineffectual.

Personal experience is poorly developed with detail, and may bear little or insufficient relation to claim. May use description, storytelling, and/or reflection only minimally or ineffectually.

Piece sometimes wanders from the claim in a way that appears unintentional.

Arrangement

Arrangement pattern is recognizable, but not effective given purpose and audience.

Paragraphing seems haphazard or unintentional.

Metadiscourse is used rarely and/or ineffectually.

Relationships among paragraphs are sometimes unclear. Paragraph sequencing is not effective.

Grammar and Mechanics

Sometimes obscure meaning, or make reading difficult. 


\section{EXCEEDS STANDARDS (e.g. a "B" paper):}

\section{Focus}

Make a claim that is both specific and sufficiently relevant to discourses concerning literacy.

Draw effectively on at least one course text related to literacy. Choice of text(s) is apt given purpose and audience.

Draw effectively on personal experience related to literacy. Choice of personal experience is apt given purpose and audience.

Working definition of literacy (may be explicit or implicit) appears reasonable and effectively interrelated to text's purpose and claim.

\section{Development}

Engages a text from the course related to literacy in a substantial way. Include sustained direct quotation and/or paraphrase and/or summary. Analysis is reasonable and developed.

Personal experience is developed with detail in such a way as to directly support the claim. Draw effectively on storytelling, description, and/or reflection.

Piece rarely wanders from the claim in a way that appears unintentional.

Arrangement

Arrangement pattern is recognizable, and reasonably effective given purpose and audience.

Paragraphing seems intentional.

Metadiscourse is used in a way as to add clarity and persuasiveness.

Relationships among paragraphs are typically clear. Paragraph sequencing is effective.

Grammar and Mechanics

Rarely obscure meaning, or make reading difficult.

SURPASSES EXPECTATIONS (e.g. an "A" paper):

Focus

Make a claim that reveals a high level of engagement in the discourse.May challenge prevailing opinions in the discourse.

Build substantially on at least one course text related to literacy. Choice of text(s) is apt given purpose and audience.

Draw compellingly on personal experience related to literacy. Choice of personal experience is apt given purpose and audience.

Working definition of literacy (may be explicit or implicit) appears reasonable is essential to text's purpose and claim.

Development

Engages a text from the course related to literacy in a highly substantive way. Include sustained direct quotation and/or paraphrase and/or summary. Analysis indicates a sophisticated understanding of the texts as part of an ongoing discourse reflected in the course.

Personal experience is developed with detail in such a way as to directly support the claim. Storytelling, description, and/or reflection are highly compelling. 
Piece does not wander from the claim, unless it is in a way that appears intentional.

Arrangement

Arrangement pattern is innovative, and highly effective given purpose and audience.

Paragraphing appears intentional and effective.

Metadiscourse is used in a way that appears natural, and adds clarity and persuasiveness.

Relationships among paragraphs are clear and overtly developed. Paragraph sequencing is highly effective.

Grammar and Mechanics

Never obscure meaning, or make reading difficult. 